\title{
Respective effects of genotype and dry matter content on maize silage feeding value
}

\author{
JC Emile, Y Barrière, $R$ Traineau \\ INRA, Station d'Amélioration des Plantes Fourragères, 86600 Lusignan, France
}

The tests presented here, and carried out with the help of the AGPM (Association Générale des Producteurs de Maïs), aim at being more specific in describing the variation factors regarding maize feeding value, and particularly digestibility. The effects of the dry matter content have been studied along with the effects of the maize genotype. This study follows those previously undertaken at INRA, outlining harvest stages (Demarquilly, 1994, Prod Anim, $7,117-189$ ) and genetic variability (Barrière et al, 1992, Euphytica, 59, 61-72).

Genotypes reputed for either their high (G1), low (G2) or medium (G3) digestibility were tested over a two year period. Two other varieties were only tested over a one year period (G4 in 1991 and G5 in 1992). Each variety was harvested and put in mini-silos either at an early date (EH, DM content nearing $27.5 \%$ ) or at a late date (LH, DM content nearing $35 \%$ ). Two repetitions were carried out on each process. During the winter months forage was given ad libitum to standard castrated wethers. Assessments were made on 6 sheep during a five day period. The voluntary DM intake (VI, g/kg LW $\left.\mathrm{W}^{0.75}\right)$ and the digestibility of the organic matter (DOM, \%) are presented herewith. The variance analysis presented regroups the 32 assessments, taking into account the Year, Genotype and Harvest Date effects and the corresponding interactions. The correlations between different descriptive criteria were also studied.

The forage average DM content given to sheep was of $28.3 \%$ for $\mathrm{EH}$ date and $35.3 \%$ for $\mathrm{LH}$ date. The daily VI were between 47 and 67 $\mathrm{g} / \mathrm{kg} \mathrm{LW} 0.75$. The main variation factor appeared to be the harvest date $(P<0.001)$. Maize harvested at an early stage was definately better ingested than that harvested at a late

\begin{tabular}{|c|c|c|}
\hline & \multicolumn{2}{|c|}{ Harvest Date } \\
\hline & $\mathrm{EH}$ & $\mathrm{LH}$ \\
\hline VI (g/kg LW0.75) & $61.7^{b}$ & $54.5^{\mathrm{a}}$ \\
\hline $\operatorname{DOM}(\%)$ & $67.1^{a}$ & $68.5^{\mathrm{b}}$ \\
\hline
\end{tabular}

stage (61.7 vs 54.5 ). This phenomena was observed in both of the two years even if less obvious in 1992 than in 1991. A significant correlation (-0.62) appeared between $\mathrm{VI}$ and DM content. The VI increased up to an DM content approaching $28 \%$, then, clearly decreased. The genotype effect was lower $P<0.05$ ), and probably overestimated by the bias in the $G 1$ variety which was systematically harvested too early.

The main variation factor of DOM was the maize genotype $(P<0.001)$. This was a very significant effect in both of the two years, the average DOM of the extreme varieties (G2 and G1) varying between 65.6 and 70.8 in 1991 and between 65.4 and 70.2 in 1992. The effect of the harvest date was lower but significant $(P<0.05)$, and without any interaction from either the year or the genotype. Forages which were harvested late appeared to be better digested than those harvested at an earlier date (68.5 vs 67.1). The absence of an obvious link between DOM and the DM content (correlation of -0.07 ), was explained by the different DOM levels of each of the varieties. However, in a given variety, DOM increased with the DM content.

Thus, the two factors studied have a significant effect on the food value of the silage given to sheep. They, indeed, influence the intake of the forage as well as its digestibility. The DOM gap between the two extreme genotypes studied corresponds to a difference of $0.07 \mathrm{UFL} / \mathrm{kg}$ DM $(0.03 \mathrm{M}$ joules), thus, confirming results put forward by Barrière et al, 1992 (Euphytica 59, 61-72). The maize silage seems to be better ingested by sheep when harvested early, but its digestibility is slightly lower $(-0.02$ UFL/kg MS). This experiment, therefore, confirms and underlines the importance of the choice of a maize variety, and of the harvest date in order to provide ruminants with good quality forage.

$\begin{array}{ccccc}\text { G1 } & \text { G2 } & \text { G3 } & \text { G4 } & \text { G5 } \\ 59.4^{\mathrm{b}} & 56.0^{\mathrm{a}} & 55.3^{\mathrm{a}} & 60.9^{\mathrm{b}} & 58.9^{\mathrm{ab}} \\ 70.5^{\mathrm{c}} & 65.4^{\mathrm{a}} & 68.4^{\mathrm{b}} & 69.3^{\mathrm{bc}} & 65.4^{\mathrm{a}}\end{array}$

